who have had much clinical experience in cholera must have noticed that one of the very earliest of its specific symptoms is a marked coldness of the tongue. It is generally easy, in the course of an epidemic, to pick out the cholera cases from those of ordinary diarrhoea by simply attending to this indication, which is readily recognisable by the touch. It is not the effect of exhaustion from diarrhoea, for it of ten occurs before diarrhca has set in. It is, probably, the immediate result of the depression produced by the impression of the poison on the nerve-centres. I simply mention this matter in illustration of my position as affirming that the first attack is on the nervous centres, or the ganglia of the sympathetic system.

The suggestion $I$ have to make is an immediate recourse to the bain electrique, at the very outset of the disease. The patient being placed in an ordinary bed, the legs of which are insulated by glass foot-cups such as are commonly used for insulating pianos, and the prime conductor of the electric machine being brought into connexion with the body, the sick person may be charged with electricity without elther trouble or pain of any sort. It is easy, with a little obvious care and precaution, to avoid discharging the electricity. For example, food and medicine may be administered with non-conducting china ware without touching the body. The effect of the electric bath is likely to prove in the early stage of cholera, as it undoubtedly proves in a certain class of cases in the early stages of fever, conservative of the vital nerve force, retarding or altogether preventing exhaustion, and, in some instances, even producing a distinct rise of the pulse, and general reaction. It is commonly supposed that static electricity has no stimulating influence, the effect produced in certain cases in which it is used being entirely due to the current set up in the act of discharging. I believe this to be an error. When nerve-centres are charged with electricity they are more stable as regards their molecular state, and whatever nerve force they happen to possess acts with greater intensity, as from a firmer base. In short, the electricity serves the purpose of a "reserve," although it is not nerve force but only approximately like it, and capable in an emergency of doing some of its work in the organism.

As an easily practicable expedient in the treatment of a malady which, under the best of circumstances is exceedingly unmanageable, I think the bain électrique should be tried. It cannot in any way interfere with the general plan of treatment which may be adopted, and in one or other of its forms holds out a fair promise of usefulness.

Welbeck-street, $\mathbf{W}$. I am, Sir, yours truly,

J. Mortimer-Granville.

\section{ASIATIC CHOLERA AND ITS INTRODUCTION INTO THIS COUNTRY.}

To the Editor of THE LANCET.

SIR,-A great deal has been written on quarantine and sanitation as a means of preventing the importation to and the spread of cholera within our own country, but I feel it is the duty of the profession to do its best by promulgating sound views to meet the progress of the disease and to allay any unnecessary feeling of alarm in the public mind. It is, I think, now pretty well admitted that cholera (the Asiatic form) is mainly propagated through the medium of bacteria or disease germs ; if it were not so, when the disease has once located itself in any position (take Cairo as an instance, where 300 deaths are occurring daily), why should the disease produce such havoc in that city? and wby, when it appears to have destroyed all the susceptible portion of a given population, should it pass on to anotber city or locality and carry out its work of destruction with equally lamentable results there? What I wish to show, supposing this theory to be sound, and supposing the cholera epidemic to fix upon any of our large cities, London for instance, what is to prevent its ravages being carried out there to a most frightful extent? It must not be forgotten that since 1844 a more extended system of underground drainage has been carried out in the metropolis, by which a quarter of a million waterclosets have been made constantly to discharge their foul contents into the house drains, and that, in consequence, at this moment there are four thousand miles of underground drains in the metropoliz, all of which are more or less choked with human excreta, and should a eholera epidemic attack London, these four thousand miles of under- ground cesspools would be the medium through which the disease would be propagated in every direction, such underground cesspools being more or less in direct communication with the interior of the dwelling-houses, some through the watercloset only, others through the various waste-pipes, \&c.; whilst the atmosphere of the streets also is polluted by exhalations and emanations from the drains and sewers through the various gully-holes, ventilators, and traps. It is a popular idea when the watercloset is used that the closet soil is instantly removed from the house drain and is conducted to the sewer's outfall at Barking Creek; but such, however, is far from being the case. In dry weather the closet soil remains in the house drains, and some of it in the soil pipe, even when vertically placed, and no amount of flushing or washing will remove it. Now, suppose we take one dry week as an example, and imagine four thousand miles of cesspools extendiog under every house and under every street throughout the metropolis; surely such a condition as that, should a cholera epidemic prevail in London, would favour its propagation in every direction. It must not be forgotten that the atmospheric current is always a backward one towards the houses, and so long as the sewage runs through and out of the sewers, so long will it remain so. Moreover, the atmospheric tempera. ture within $d$ welling-houses being higher than that of the drains and sewers it is obvious that the tendency of the foul gases in the drains and sewers will be to rise into the houses and streets. All kinds of schemes are being devised by modern sanitarians, who are aware of the evil they have created, such as cutting off the connexions of waste-pipes, \&c. from lavatories, bath-rooms, and sinks with the drains; but that is a complete admission of the failure of their system, for if the drains were not polluted by human excreta, surely it would not be necessary to sever the connexion with them. The real evil lies in allowing the solid excreta to be discharged into the drains at all; that material is so viscid and tenacious that it is impossible, even with the most effective flushing, to free the drains from it. If the attention of the Local Government Board is not drawn to this subject, so that that body may be made thoroughly to com. prenend the danger, I fear the results of a cholera epidemic in London, should it occur, will be frightful to contemplate. In the report on urban diarrhoea mortality, July 14th, I notice 249 deaths occurred in the week ending that date from diarrhoea in the twenty-eight principal towns; 167, or two-thirds of the whole number, occurred in London alone, and if the mortality from diarrhœe is so exceptional in London, surely we may expect the mortality from cholera will be equally excessive. The urgent importance of the subject must be my apology for troubling you with these few lines. I am, Sir, yours truly,

Birmingham, July, $1883 . \quad$ EDWIN CHESSHIRE, F.R.C.S

\section{SCOTTISH NOTES : UNIVERSITY OF ST. ANDREWS. \\ To the Editor of THE LANCET.}

SIR,-With regard to the article under the above head. ing, which appeared in your issue of the 14th inst., giving quotations from a memorial to the Lord Advocate by the Medical Faculty of the University of St. Andrews, I beg to state that the quotations selected are calculated to mislead, from not giving both sides of the question. Your inference is calculated still further to mislead, as you conclude your article with the following words :- "These main contentions are supported by a long list of arguments, weighty of themselves, but all tending - and this is the chief point to the profession-to withdraw St. Andrews from even the semblance of purely medical teaching now existing. Drs. Pettigrew, McIntosh, and (with some reservation) Heddle sign the document from which the above quotation is taken; and in the further consideration of this and other matters, it will not be unfuir to assume [the italics are mine] that these gentlemen aspire only to complete incorporation in an extended Faculty of Arts." Now, so far from the Medical Faculty of the University of St. Andrew s seeking dissolution and "complete incorporation in an extended faculty of arts," it is distinctly stated in the memorial referred to that the Medical Faculty desire a fourth medical chair, in order to be able to give two anni medici. The followifg clauses from the memorial will verify this statement:- "The most St. 
Andrews could hope to do in such a direction is to get another medical chair instituted, to enable it to give two anni medici. The most fitting chair for this purpose would be a conjoined chair of botany and materia medica, which would at the same time qualify for the extended Master of Arts degree." "By retaining the three medical chairs (to which it is to be hoped a fourth will be added) at St. Andrews, the medical professors would be doubly useful, inasmuch as they would educate medical students as well as art students." This being so, I wish to state, as Dean of the Medical Faculty, that nothing can be further from the intentions of the faculty which I represent than the abandoning of medical teaching or the giving up of any powers which we possess as a medical examining and medical degree conferring body; and I will feel greatly obliged by your giving this letter all the publicity in your power, as the subject is one which deeply concerns the University of St. Andrews. I remain, Sir, yours, \&c.,

J. BELL PETTIGREW, M.D., F.R. S., Dean of the Medical Faculty, \&c.

Unfrersity of St. Andrews, July 25th, 1883.

\section{"ON RUPTURE OF THE URINARY BLADDER."}

To the Editor of THE LANCET.

SiR,-The criticisms to which, after a long silence, $\mathrm{Mr}$. Morris has subjected portions of my paper on "Rupture of the Urinary Bladder," published last year in THE LANCET, necessitate a reply. Mr. Morris seems to complain of my laring included his reported case of recovery in the intraperitoneal series, although he had described the wound as "chiefly, though perhaps not entirely, extra-peritoneal." But the half belief of Mr. Morris in the existence of an intraperitoneal rent, however limited, through wbich, I presume, urine could have entered the peritoneal cavity, overshadowed the larger extra-peritoneal rent, and did not admit of any other course. If I understand Mr. Morris correctly, he now closes the dubious rent in the peritoneum altogether. This is a solid gain, which I am most thankful to accept, and I regret that $I$ am unable at once to reciprocate the concession by altering my opinion as to the nature of his case. Mr. Morris characterises my summary of his case as a little misleading. It was not intentionally so, and I now take special note that his patient stated that "he had not passed water for an hour or two" (I used the expression "about an hour"), that he was drinking up to the moment of wrestling, and that there was a certain or uncertain proportion of blood in the three-quarters of a pint of fluid which he passed during the first thirty-six hours. Some space in $\mathrm{Mr}$. Morris's paper is occupied with attributing to me arguments and opinions which $I$ have not advanced, and then proceeding to refute them with the help of material which I have abundantly furnished. Thus $I$ am made to argue that a bladder is not ruptured because thirty-six hours after the injury the patient passes water by his own efforts, and because, subsequently, plenty of urine can be daily drawn off as soon as he comes under observation. Possibly some instances which Mr. Morris gives to refute these imaginary generalisations of mine might, if critically weighed, tend rather to support them than otherwise, but inasmuch as I did not apply the facts of Mr. Morris's case as absolute general statements, it would be waste of time and space to point out flaws in the refutation. In Part II. of my paper I referred to cases in which patients with ruptured bladders voluntarily passed more or less water at variable periods after the injury, and gave prominence to the fact that large quantities of urine might be drawn off, and, therefore, I am not likely to make unqualified general statements at variance with instances with which $\mathrm{I}$ am familiar. Nevertheless, it is most important to bear in mind two things. First, the amount of urine obtainable from a ruptured bladder varie from none at all to a few ounces. The larger quantities drawn in some of the published cases came from the peritoneum or from an adventitious cavity outside the bladder. What the rule may be when a catheter is tied in, my notes do not enable me to determine, but I suspect that the normal quantity would not be obtained. In Mr. Hird's intra-peritoneal case (THE LANCET, 1846) the catheter was tied in, and brought very little urine away throughout the day, Secondly, desire with inability to micturate often from first to last is the common condition after rupture of the bladder. Tae passage of urine by the unaided efforts of the patient is exceptional. I cannot refer to any published and authenticated case in which as much as three-quarters of a pint of bloody urine (I do not include the dribblings of incontinence) were passed voluntarily in instalments during the first thirty-six hours by a male patient. If, then, regard be paid to the symptoms alone in $\mathrm{Mr}$. Morris's case, they are decidedly more favourable to the soundness than to the rupture of the bladder; but the genuineness of the rupture, whether intra-peritoneal, extraperitoneal, or a combination of both, turned in my view upon the condition of the bladder at the time of the accident. If conclusive proof had been afforded that the bladder contained any considerable quantity of urine, I must have acquiesced in the diagnosis, notwithstanding the great difficulty of accounting for the effused urine ; for I cannot imagine that any ordinary distended bladder could withstand the kneading with the knees to which the abdomen was subjected. At present, I consider the evidence of distension defective, as it consists merely of an inexact and inconclusive statement of a tippling patient, that "he had not passed water for an hour or two and had been drinking up to the moment of wrestling." What is wanted is some precise and reliable proof of imbibition of a sufficient quantity of fluid taken in time to reach the bladder. Until this is forthcoming, I feel justified in still regarding the case as one of severe contusion. The symptoms are compatible with this explanation, and the improbabilities in volved in the acceptance of the diagnosis are far greater than any contained in the supposition that the patient did not give an accurate history, and that the surgeon was misled by too confiding a trust in the loose statements of a fallible patient. Mr. Morris very fairly alludes to a case which I related, showing that an extra-peritoneal rupture near the neck of the bladder may occur when the bladder is empty or contains at the most a few ounces of urine, by being dragged backwards with the peritoneum. Fxceptionally, I believe that this may happen; but I also think that it can only happen through an amount of contusion and stripping up of the peritoneum, almost inevitably fatal to the patient. In my own case, death took place on the third day, and diffase inflammation had commenced as a result of the contusion, and the passage of urine through the rent in the bladder. Hence, I doubt whether my case will give $\mathrm{Mr}$. Morris much assistance, if he is prepared to admit that the bladder of his own patient might not have contained, at the time of the accident, so much urine as his patient's account led him to believe. Mr. Morris has my thanks for his acumen in detecting constructible error in my mode of stating that the reported cases of recovery might be disregarded in considering the question of treatment, owing to the bewildering results which would attend the admission of their genuineness for the purpose of the discussion. He proceeds, however, to interpret my remarks as equivalent to questioning the genuineness of the cases on the ground of mere diversity in the treatment supposed to have been successful. Undoubtedly the genuineness of the reported cases of recovery must stand or fall upon their intrinsic merits or defects, and my practical recognition of this principle has been so ample that $I$ know not when I shall be released from replying to the authors of the cases which I have critically reviewed. Moreover, I fully agree with Mr. Morris in the opinion, which he bas happily exemplified from the treatment of popliteal aneurism, that there may be various effectual ways, apparently different, but in reality similar in principle, by which the same end may be effected. On the other hand, let it not be forgotten that there may be several inefficient methods of treating a par. ticular disease whose continued use is bolstered up by the publication of illusory cases of recovery; and underlying my remarks was the profound conviction that the treatment adopted in some of the reported cases of recovery after intra-peritoneal rupture of the urinary bladder was, in varying degrees, inadequate and unreliable. This constitutes an important difference between popliteal aneurism and ruptured bladder. Other differences are that in popliteal aneu. rism the diagnosis is usually obvious, and the means of carrying out well-established principles of treatment cau have their value proved by unquestioned instances of success, whilst in intra-peritoneal rupture of the bladder the diagnosis is beset with fallacies, and authenticated cases of recovery are still wanting to decide between the conflicting claims of the different plans advocated by different surgeons. In popliteal aneurism, if milder methods fail, the nore radical can be adopted with every prospect of sucecss. In 